\title{
Injury in Review, 2012 Edition: Spotlight on Road and Transport Safety
}

\author{
M. Cardinal, MSc; J. Crain, MA; M. T. Do, PhD; M. Fréchette, MSc; S. McFaull, MSc; R. Skinner, MSP; \\ W. Thompson, MSC
}

\begin{abstract}
Injury in Review, 2012 Edition: Spotlight on Road and Transport Safety, the first national public health report of its kind, synthesizes road- and transportrelated injury statistics from a variety of sources. It profiles injury patterns among Canadians aged up to 24 years, explains risks and protective factors, and makes recommendations for action. The findings inform the development of targeted injury prevention efforts.
\end{abstract}

\section{Introduction}

Injuries* are the leading cause of death among Canadians aged 1 to 44 years and the fourth leading cause of death among Canadians of all ages. Many non-fatal injuries result in impairments and disabilities such as blindness, spinal cord injury and intellectual deficit due to brain injury. Between 1979 and 2007 (the year of the most recent available data for all provinces and territories at time of publication), the number of road fatalities in Canada decreased by $73 \%$; however, motor vehicle traffic collisions remain the leading cause of injury death among Canadians aged 1 to 24 years.
The current report presents national surveillance statistics on injury and mortality in Canada from the leading causes, including road- and transportrelated causes, among children, youth and young adults aged up to 24 years. ${ }^{\dagger}$ It also contains important information and tips for young people, parents, caregivers and others interested in helping to prevent road- and transport-related injuries.

\section{Select Results}

Mortality

Injury was the leading cause of death among Canadians aged 1 to 44 years and the fourth leading cause of death among all Canadians of all ages in 2007 . Suffocation was the leading cause of injury-related mortality among infants ( $<1$ year), while motor vehicle traffic (MVT) collisions led among those aged 1 to 24 years, suicide among those aged 25 to 69 years, and falls among those aged 70 years or older.

In 2007, of every 100000 Canadians aged under 25 years, 19 were fatally injured, 7 as a result of unintentional MVT-related collisions. MVT-related deaths have declined sharply since the early 1970s; most notably, the mortality rate for those aged 15 to 24 years declined from 46.4 per 100000 population in the early 1970 s to 15.0 per 100000 population in 2007. It is important to note that this dramatic decline started within two years of the introduction of mandatory seat belts in all new cars in 1971.

In 2007, 20- to 24-year-old men were 3 times more likely to die in MVT collisions than were women in the same age group.

\section{Hospitalization}

In 2008/2009, ${ }^{\neq}$injury was the leading cause of hospitalization among Canadians aged 10 to 24 years and the third leading cause of hospitalization among Canadians of all ages. Falls were the leading cause of injury-related hospitalization overall; however, among 15- to 19-year-old youth, intentional self-harm was the leading cause of hospitalization. Of every 100000 Canadians aged under 25 years, 418 were hospitalized due to injuries in general and 46 due to unintentional MVT collisions. In the same period, 20- to 24-year-old men were almost twice as likely to be hospitalized for injury compared with women (odds ratio $[\mathrm{OR}]=1.8$ ) .

\footnotetext{
* All causes of injury (intentional and unintentional) excluding adverse effects due to medical or surgical care.

† Alcohol-related mortality statistics also refer to older age groups.

₹ Hospitalization data are traditionally reported according to a fiscal year beginning April 1 and ending on March 31 the following year. Canadian Hospitals Injury Reporting and Prevention Program (CHIRPP) statistics are also presented by fiscal year to allow for timely reporting on the most recent data available and for comparability with hospitalization statistics.
} 


\section{Off-highway vehicle-related injuries}

Data for 2008/2009 from the Canadian Hospitals Injury Reporting and Prevention Program (CHIRPP) $)^{\S}$ show that the proportion of young Canadians (0-24 years of age) admitted to hospital for off-highway vehicle $(\mathrm{OHV})$-related injuries was almost twice that of those admitted for MVT-related injuries, at $24.8 \%$ versus $13.8 \%$, respectively. The number of injuries reported by CHIRPP increased almost 3-fold for all-terrain vehicles (ATVs) from 1990/91 to 2008/09.

Of the OHV-related cases involving children aged 11 to 15 years, the proportion of these underage drivers injured while in the driver's seat was $60 \%$ for ATV-related injuries, $48 \%$ for snowmobiles, and $92 \%$ for dirt bikes, proportions similar to those observed for 0- to 24-year-olds. For young adults aged 20 to 24 years, the number of ATV-related injuries was more than twice that of dirt bike-related injuries; almost half of all injuries associated with OHV-related collisions among those under 25 years old were fractures.

\section{Vulnerable road users}

Vulnerable road users (VRUs) are defined as roadway users who are unprotected by any vehicle structure, for example, cyclists. In the event of a crash, VRUs are susceptible to injury or death due to mass differential. VRUs can be classified as powered or non-powered. Injury in Review, 2012 Edition presents annual proportions of non-powered and powered VRU cases reported to CHIRPP, including, for example, pedestrians, pedal cyclists, motorcyclists, and moped and scooter riders.

\section{Restraint use for motor-vehicle occupants}

Based on data from Transport Canada's National Collision Database, between 1998 and 2008, unrestrained occupants of light-duty vehicles (passenger cars, light trucks, vans and sport-utility vehicles [SUVs]) involved in collisions were 3 times more likely to be injured ( $\mathrm{OR}=3.4$ ) and 16 times more likely to die as a result of injuries (OR $=15.7$ ) sustained in collisions compared with the occupants who used restraints.

\section{Alcohol-related mortality}

Based on data from the Traffic Injury Research Foundation's Fatality Database,** $38 \%$ of motor vehicle-related fatalities in Canada in 2009 involved alcohol use, with males approximately twice as likely to die in alcohol-related collisions compared with females (OR $=2.3$ ). From 1998 to 2009 , there was no significant decrease in the annual proportion of motor vehicle-related fatalities involving alcohol use, ${ }^{\dagger+}$ demonstrating the need for further prevention efforts.

\section{Economic burden}

Injury impacts the families of those who are injured and society as a whole. From a health-oriented perspective, the economic burden of unintentional and intentional injuries in Canada, for all causes and ages combined, was estimated to be $\$ 19.8$ billion in 2004 (including both direct and indirect costs), 19\% of which related to transport incidents alone. ${ }^{1}$

\section{Next steps}

Surveillance statistics show an important decline in the rates of motor vehicle traffic-related injuries over the past three decades. Nevertheless, injuries, and in particular transport-related incidents, are a major public health challenge in Canada, and further injury prevention efforts are necessary. The Public Health Agency of Canada (PHAC) continues to collaborate with Health Canada, Safe Kids
Canada, the Traffic Injury Research Foundation and other partners to research and advance knowledge and road safety policies and programs. Together we are contributing to making Canada a safer place for road users.

Ordering instructions for Injury in Review, 2012 Edition: Spotlight on Road and Transport Safety are available at http:// www.phac-aspc.gc.ca/injury-bles/ chirpp/injrep-rapbles/index-eng.php.

\section{Acknowledgements}

Injury in Review, 2012 Edition: Spotlight on Road and Transport Safety was produced by the Public Health Agency of Canada in collaboration with Safe Kids Canada and the Traffic Injury Research Foundation. PHAC would like to express its appreciation to all collaborators for their valuable role in this project.

\section{References}

1. SMARTRISK. The Economic Burden of Injury in Canada. Toronto $(\mathrm{ON})$ : SMARTRISK; 2009.

\footnotetext{
$\S$ The Canadian Hospitals Injury Reporting and Prevention Program (CHIRPP) is an injury surveillance system that collects and analyzes data on injuries, mainly to children, seen at the emergency rooms of the 11 paediatric hospitals and 4 general hospitals in Canada. CHIRPP is a unique, richly detailed database of injury information.

** The Fatality Database is developed and managed by the Traffic Injury Research Foundation. The following agencies have provided funding for the Fatality Database: Health Canada (1973-1982); Transport Canada and the Canadian Council of Motor Transport Administrators (1984-2010; their funding for the Database has been in support of the Strategy to Reduce Impaired Driving for several years).

" Fatalities are considered to be alcohol-involved if the fatally injured person was a driver or pedestrian who had been drinking or if at least one driver involved in the collision had been drinking; passenger fatalities are also considered to be alcohol-involved if one of the drivers involved had been drinking. The percentage of alcohol-involved fatalities is calculated from the number of deceased persons categorized as an alcohol-involved fatality, divided by the total number of cases where alcohol involvement in the collision was known.
} 